\title{
Understanding Couples' Relationship Quality And Contraceptive Use in Kumasi, Ghana
}

CONTEXT: A wealth of data exist on knowledge, attitudes and practice related to contraceptive use; however, emotional aspects of relationships that may influence reproductive decision making are often overlooked.

METHODS: Data from the 2010 Family Health and Wealth Survey were used in bivariate and multinomial logistic regression analyses to identify associations between relationship quality and current contraceptive use among 698 married or cohabiting couples in Kumasi, Ghana. Four scales measuring commitment, trust, constructive communication and destructive communication, as well as a question about relationship satisfaction, were the indicators of relationship quality. Current contraceptive use was divided into three categories: no use, reliance on a method that can be used without the partner's awareness (the injectable, pill, IUD, implant and diaphragm) and use of a method that both partners are typically aware of (periodic abstinence, withdrawal, condoms and spermicide).

RESULTS: Overall contraceptive use was low-22\% of women said they were currently using any method. In general, respondents reported high levels of relationship quality. Women's relationship satisfaction scores were positively associated with use of awareness methods rather than nonuse (relative risk ratio, 1.2). Men's trust scores were positively associated with use of nonawareness methods rather than nonuse (1.1), and men's constructive communication scores were associated with use of both types of method rather than nonuse (1.1 for each).

CONCLUSIONS: Couples' relationship quality appears to be an important element in their decision making regarding contraceptive use, and should be taken into consideration in the design and implementation of family planning programs and policy.

International Perspectives on Sexual and Reproductive Health, 2013, 39(4):185-194, doi: 10.1363/3918513

In 1994, the International Conference for Population and Development (ICPD) shifted global thinking on reproductive health from a population-based approach to a rights-based approach. With this shift came a heightened awareness of how gender relations and equality can influence sexual and reproductive rights. The ICPD program of action declared that "human sexuality and gender relations are closely interrelated and together affect the ability of men and women to achieve and maintain sexual health and manage their reproductive lives." ${ }^{\prime(p . ~ 48) ~ P r o m o t i n g ~}$ and achieving respectful and equitable gender relations through harmonious partnerships were key elements in several of the program's objectives. To fulfill the ICPD commitments, a better understanding of how partners relate to one another, how to assess relationship quality, and how partners' relations promote or inhibit sexual and reproductive desires and decisions is needed. These topics have received little research attention in Sub-Saharan Africa.

In response to this gap in research, we designed this study to improve our understanding of how various dimensions of relationship quality of married or cohabiting partners in Kumasi, Ghana, are related to contraceptive use. We focus on five dimensions of relationship qualitycommitment, trust, constructive communication, destructive communication and satisfaction.

\section{Relationship Quality and Contraceptive Use}

According to the Guttmacher Institute and the United Nations Population Fund, 222 million women in developing countries had an unmet need for family planning in 2012 these women wanted to space or limit childbearing but were not using a modern contraceptive method. ${ }^{2}$ While rates of contraceptive use are increasing in some regions, West Africa has mainly experienced stagnant and in some cases decreased use of contraceptives. Extensive research has been conducted to identify characteristics associated with women's contraceptive use and nonuse throughout the world, including Sub-Saharan Africa. Over the last two decades, research has increasingly focused on how contraceptive use may be related to couple characteristics and relationship dynamics. ${ }^{3-9}$

Nearly all sexual and reproductive decisions made within intimate relationships affect both partners, even when only one partner is making the decision. Women's lack of power and autonomy in intimate relationships has been recognized as a reality for many women in Sub-Saharan Africa, and the detrimental effects on their health and livelihood have been assessed. ${ }^{6,10,11}$ A number of studies have examined the dimensions of couple dynamics in relation to sexual and reproductive health, including intimate partner violence, ${ }^{4,5,12}$ household decision-making power ${ }^{6,7,10,13}$
By Carie Muntifering Cox, Michelle J. Hindin, Easmo Otupiri and Roderick LarsenReindorf

Carie Muntifering Cox is a research scientist, Department of Family Medicine, University of Washington, Seattle, WA, USA. Michelle J. Hindin is associate professor, Department of Population, Family and Reproductive Health, Johns Hopkins Bloomberg School of Public Health, Baltimore, MD, USA. Easmon Otupiri is senior lecturer, Department of Community Health, and Roderick E. Larsen-Reindorf is lecturer, Department of Obstetrics and Gynecology-both at the School of Medical Sciences, Kwame Nkrumah University of Science and Technology, Kumasi, Ghana. 
and partner communication about family planning. , $^{3,10,14}$ These studies provide evidence of the important and complex role that relationship dynamics play in contraceptive use in Sub-Saharan Africa. Despite the increased attention paid to relationship dynamics, a limited number of studies have looked specifically at dimensions of relationship quality and contraceptive use in this region. ${ }^{15-18}$

Much of the research on relationship quality and contraceptive use in Sub-Saharan Africa has been conducted in the context of HIV, with a focus on condom use. ${ }^{16,18}$ In a qualitative study in Uganda, discussions about and use of condoms within committed relationships were reported as difficult and as suggesting a lack of trust in one's partner. ${ }^{18}$ The same study found that female-controlled barrier methods were viewed as a means for women who do not trust their partners to protect themselves. Findings from another African study suggest that as trust grows within a relationship, condom use decreases, ${ }^{16}$ which is consistent with evidence from studies conducted in developed countries. ${ }^{19,20}$

Few studies from Sub-Saharan Africa have examined the association between relationship quality and contraceptive methods other than condoms. ${ }^{15,17,18}$ Two studies showed that some men fear that wives who use contraceptives may be unfaithful or may abandon their husbands; this fear and mistrust influence men's acceptance of their partner's contraceptive use. ${ }^{15,18}$ In a study conducted in northern Ghana, respondents noted that women sometimes avoid discussing or using contraceptives out of fear of how their spouses will react, and many respondents believed that discussing contraception could result in a quarrel or in intimate partner violence. ${ }^{15}$ Because of perceived male opposition to contraceptive use and men's desire for large families, women feared that use of contraceptives without their husband's knowledge or approval would harm their relationship, decrease intimacy and affection, and even result in the husband taking an additional wife if he were to find out about his partner's use. The single study that linked contraceptive use and relationship quality found that use was correlated with both marital and sexual satisfaction. ${ }^{17}$ In developed countries, researchers have primarily examined relationship quality and contraceptive use among unmarried adolescents, ${ }^{21,22}$ and often focus on condom use. ${ }^{20,23}$ Few studies have focused on this topic among adults in steady or long-term relationships, and several include only young adults in their sample. .9,24-26 $^{-26}$

Research suggests that relationship quality does play a role in contraceptive decision making, but the direction and strength of the association vary by dimension of relationship quality and method. ${ }^{19,24-26}$ It appears that whether relationship quality is associated with an increase or decrease in women's likelihood of using contraceptives depends on specific circumstances; ${ }^{19,26}$ however, the research is limited. Understanding the nuances of how different dimensions of relationship quality may influence method use is important for the development of targeted interventions.

\section{Study Context}

This analysis used data from married or cohabiting couples residing in two peri-urban communities in Kumasi, Ghana. This is the second largest city in Ghana and is located in the Ashanti region.

- Relationship dynamics. Marriage is nearly universal in Ghana. The median age of marriage is 20 for women and 26 for men. ${ }^{27}$ Marriage dissolution is not uncommon; a study using 2003 nationally representative data estimated that about one-quarter of ever-married women had experienced divorce. ${ }^{28}$ Eighteen percent of married women report living in a polygynous union, ${ }^{27}$ which is particularly important when considering relationship quality and health outcomes. In a 2009 literature review on polygyny and women's health, ${ }^{29}$ Bove and Valeggia found that compared with monogamous unions, polygynous unions are associated with less spousal communication and reduced coital frequency, and that polygynous men have higher rates of extramarital sexual relations than monogamous men. Furthermore, women in polygynous unions report lower life satisfaction than do women in monogamous unions.

Since the early 1960s, Ghana has been experiencing a shift away from traditional arranged marriages, in which parents are involved in selecting their children's partners, to romantic marriages, in which men and women select their own partners. ${ }^{30}$ The Ghana Female Autonomy Micro Study revealed that in 1992, $76 \%$ of husbands and $68 \%$ of wives had selected their partner without help or consent from their family. ${ }^{31}$ Despite this shift, kinship ties are still influential in marital quality and stability. ${ }^{28,32}$ One hypothesis is that strong allegiance to kin weakens the bond between married partners, especially in matrilineal kinships. $^{32}$

A limited number of studies have examined relationship quality in Ghana. ${ }^{33,34}$ In the Upper East Region, men whose relationships were characterized by less traditional decision making and more open communication were more likely than others to report higher relationship quality. ${ }^{33}$ A study on marital conflict conducted in Cape Coast identified major causes of conflict, including spousal attributes, domestic family life, sociocultural and socioeconomic characteristics, and inequality. ${ }^{34}$ Furthermore, consequences of marital conflict were described as both psychological and physical. In the 2008 Demographic and Health Survey, 20\% of ever-married women reported having experienced physical or sexual violence by a husband or partner in the past 12 months, and 31\% reported emotional violence. ${ }^{27}$ Ten percent of ever-married men had experienced physical violence at the hands of a wife or partner in the past year, and 23\% had suffered emotional violence.

- Contraceptive use. Ghana has a low rate of contraceptive prevalence and a high level of unmet need. In 2008, $24 \%$ of currently married women reported using any contraceptive method and $17 \%$ a modern method; the latter represents a two-percentage-point decrease from $2003 .{ }^{27}$ 
An estimated 35\% of women have an unmet need for family planning; however, only $48 \%$ of current nonusers intend to use a modern method in the future. Reasons for not intending to use a method include infrequent sexual intercourse, ${ }^{13}$ opposition to use (by self or others), lack of knowledge and method-related reasons (e.g., side effects). ${ }^{27,35}$ On the supply side, family planning services are provided by many types of facilities, including hospitals, public and private clinics, and pharmacies, as well as by community-based distribution through the Ghana Health Services. ${ }^{27}$ While the availability of contraceptive services improved in Ghana between 1993 and 2002-with 96\% of facilities offering services at least five days a week-lack of demand and stockouts ${ }^{36}$ may partially explain why contraceptive use remains low.

\section{Theoretical Framework}

We used the tenets of Family Systems Theory as a framework for our study. ${ }^{37}$ This theory recognizes that individual behavior within a system cannot be understood in isolation, and that the interrelationships among the members of a system must be considered when examining individual and group behavior. Family systems theorists believe that each family, or in our case the couple, works by maintaining and regulating relationships between individuals through their decisions and actions. These decisions and actions, as well as how actions alter the status of the relationship, are related to both individualand couple-level attributes, including the quality of the couple's relationship.

In applying the family systems framework to our study, we assume that an individual's or couple's decision to discuss, initiate or continue use of a contraceptive is in part influenced by the current quality of their relationship, as well as by how the action will maintain or change that quality. As suggested by other researchers, context can change the influence of relationship quality on contraceptive use. ${ }^{26}$ For example, a woman in a low-quality relationship might be more hesitant or afraid to discuss or use contraceptives with her partner than a woman in a higher-quality relationship. Yet the same woman might be more motivated to avoid having a child (or another) with her current partner because of the quality of the relationship, and if contraceptives are accessible (either openly or covertly), she might be more likely to use a method than a woman in a higherquality relationship.

To assess if and in what direction relationship quality is associated with contraceptive use in Kumasi, Ghana, we examined five different dimensions. These measures were selected from a larger ongoing study that had used previously validated scales. ${ }^{38-42}$

\section{METHODS}

\section{Data and Sample}

The data for this analysis come from the Family Health and Wealth Study (FHWS), a longitudinal study of married and cohabiting couples in Kumasi conducted by the
Kwame Nkrumah University of Science and Technology in collaboration with the Gates Institute for Population and Reproductive Health. We used the baseline data, which were collected in August 2010; this was the only round of data available at the time of analysis. A total of 800 couples of reproductive age (18-44 years for women and 18-59 years for men) were randomly selected and surveyed. Interviewers identified a private space in which the men and the women completed the survey separately; neither partner was present during his or her partner's interview.

In multifamily households, only one couple was selected to participate. In polygynous unions, only one wife was selected. If more than one wife was present at the time of recruitment, the first-married wife was screened and, if eligible, selected. If she was ineligible, refused to participate or was not home, then the second wife was screened for eligibility, and so on.

Forty-eight couples were excluded from the current analysis because the woman was pregnant and had not had a need for contraception at the time of the pregnancy. Two couples in which the woman reported having been sterilized were excluded because the decision to be sterilized may have occurred long before the survey and thus prior to reporting on relationship quality. Furthermore, sterilization is a permanent method and does not require continued decision making by the individual or couple. In addition, six women who selected "other" from the list of method options for current contraceptive use were excluded because we were unable to categorize them into an appropriate group.

Information on relationship duration was missing for $5 \%$ of the couples. To retain this important variable without losing a substantial proportion of our sample, we sorted these couples by age and imputed duration values using the hot deck imputation method. Hence, all couples who were missing these values were assigned the value of the couple immediately prior to them in the sorted-by-age data set. Twenty-three couples with missing values for any other covariate were dropped from the analysis.

We assessed the impact of excluding groups of respondents on the basis of certain characteristics. We initially created three categories of religion (Christian, Muslim and other); however, because only 23 women in the "other" category reported current contraceptive use, we excluded these couples, and a sensitivity analysis assessing the impact of their exclusion showed little change in the results. Women who were not using contraceptives were asked the following question: "What is the main reason that you think you will not use a contraceptive method at any time in the future?" Eighteen respondents selected "menopause/hysterectomy," and a sensitivity analysis found that their inclusion had little impact on the results. Since the only estimates of these experiences came in response to a question on contraceptive use-and hence the responses may have lacked reliability-we decided to keep these respondents in the analysis. In total, 698 couples were included in the analytic sample. 


\begin{tabular}{|c|c|c|}
\hline Variable & Item & $\begin{array}{l}\text { Likert scale } \\
\text { range/item }\end{array}$ \\
\hline Commitment Subscale & $\begin{array}{l}\text { I expect my love for my current partner to last for the rest of my life } \\
\text { I view my relationship with my current partner as permanent } \\
\text { I am committed to maintaining my relationship with my current partner } \\
\text { I have confidence in the stability of my relationship with my current partner }\end{array}$ & $1-9$ \\
\hline Trust Scale & $\begin{array}{l}\text { My partner is perfectly honest and truthful with me } \\
\text { I feel I can trust my partner completely } \\
\text { My partner is truly sincere in his/her promises } \\
\text { My partner treats me fairly and justly } \\
\text { I feel that my partner can be counted on to help me }\end{array}$ & $1-7$ \\
\hline Constructive Communication Subscale & $\begin{array}{l}\text { We try to discuss the problem } \\
\text { We express our feelings to each other } \\
\text { We suggest possible solutions and compromises }\end{array}$ & $1-10$ \\
\hline Destructive Communication Subscale & $\begin{array}{l}\text { We threaten each other with negative consequences } \\
\text { I call my partner names, swear at him/her or attack his/her character } \\
\text { My partner calls me names, swears at me or attacks my character }\end{array}$ & $1-10$ \\
\hline Satisfaction & Please rate how happy you are in your relationship & $1-6$ \\
\hline
\end{tabular}

\section{Variables}

- Dependent variable. Our dependent variable is women's current contraceptive use, divided into three categories: no use (the reference group), use of a nonawareness method and use of an awareness method. Nonawareness methods are those that can be used without the male partner's knowledge: the injectable, pill, IUD, implant and diaphragm. Of course, these methods are not always used covertly. Awareness methods typically cannot be used without both partners' knowledge, and include periodic abstinence, withdrawal, condoms and spermicides.

The rationale for using these categories was based on the objective of this analysis-to identify associations between couples' relationship quality and contraceptive use. We hypothesized that the association between relationship quality and use would depend on how involved one's partner needs to be in the decision to initiate or continue use of specific methods.

-Independent variables. Our key independent variables assessed five dimensions of relationship quality, as reported by both women and men: commitment, trust, constructive communication, destructive communication and relationship satisfaction. This last dimension was measured by a single question that asked respondents to "rate how happy you are in your relationship." The other measures were adapted from validated scales. For all relationship quality items, respondents were asked to indicate their level of agreement using a Likert scale in which the lowest score was 1 and the highest score varied by scale (from 6 to 10).

*The original Constructive Communication Subscale, which was developed by Heavey et al., ${ }^{40}$ measured both constructive and destructive communication, which we analyzed as separate variables so that we could assess the two constructs independently. Furthermore, when both subscales are combined into one scale, the score is calculated by subtracting the destructive communication score from the constructive communication score; hence individuals who score similarly on both subscales will also have similar overall scores, regardless of whether the individual scores were high, low or somewhere in between. We felt it was important to keep these groups of individuals distinct, and thus analyzed the subscales separately.
The Commitment Subscale, adapted from the Sternberg Triangular Love Scale, ${ }^{38}$ is based on four items regarding a person's current love for their partner and long-term commitment to their relationship (Table 1). The five-item Dyadic Trust Scale is adapted from a scale developed by Larzelere and Huston ${ }^{39}$ to measure interpersonal trust in a relationship. Benevolence and honesty are the two attributes of trust assessed by this scale. The Constructive Communication Subscale and Destructive Communication Subscale are adapted from the Communication Patterns Questionnaire. ${ }^{40,41}$ The first subscale measures the frequency of a couple's constructive communication behavior during times of conflict, and includes three items assessing mutual discussion, expression and negotiation. The second subscale measures the frequency of a couple's destructive communication behavior during conflict; its three items assess threatening and verbal aggression to and from one's partner.*

All scales were additive; however, some items required reverse scoring, which was done before summing the total score for each. For every scale other than destructive communication, a high score is more desirable. In a previous study, a confirmatory factor analysis of the scales was conducted using the FHWS data and a good fit was obtained after respecifying the scales by dropping items with low factor loadings. ${ }^{43}$ (Table 1 shows only the retained items following this analysis.) All scales showed high internal consistency, with Cronbach's alphas above 0.80.

We included other independent variables that are commonly believed to be associated with contraceptive use. Social and demographic variables were women's age, education and religion; household and couple characteristics were household wealth, relationship type (in a monogamous or polygynous union as reported by the woman), relationship status (married or cohabiting), relationship duration, differences in age and education between partners, and number of children. Ownership of assets and the presence of certain household characteristics were used to 
create a wealth score for each household through principal components analysis; scores were placed in rank order and divided into quintiles. *

\section{Analysis}

Exploratory data analysis was conducted to examine the data for frequencies, distributions and missing variables. Bivariate analysis was then conducted to identify unadjusted associations between contraceptive use and the independent variables, followed by multivariate analysis. Given the categorical nature of the outcome variable, multinomial logistic regression models were used for both bivariate and multivariate analyses.

To identify independent associations with contraceptive use, we used separate multivariate models for each of the five dimensions of relationship quality. Furthermore, for each dimension we conducted three analyses using data on relationship quality from women's reports (not shown), from men's reports (not shown) and from both. We observed only slight attenuation in the relative risk ratios when including both partners' scores instead of one partner's; thus we present results for the combined models. The multivariate models adjusted for all the social, demographic, household and couple characteristics. The majority of these variables were significant in bivariate analysis; however, four were not. Since these last four variables have been associated with contraceptive use in previous research, we chose to retain them in the multivariate analysis.

Teams of two interviewers, one of each sex, were assigned to each of four geographic areas (clusters of neighboring enumeration areas) to match the sex of the interviewer and respondent. Couples living within geographic areas and thus interviewed by the same team are likely correlated. To account for this potential nonindependence, we clustered couples by interviewer.

The FHWS was approved by the Committee on Human Research Publication and Ethics at the School of Medical Sciences, Kwame Nkrumah University of Science and Technology, and by the institutional review board at Johns Hopkins Bloomberg School of Public Health.

\section{RESULTS}

\section{Sample Characteristics}

Women's mean age was 34, and on average their partners were eight years older (Table 2). Women had an average of six years of education, and their partners had nearly a year more. About half of women were Christian and half were Muslim. More than nine in 10 couples were in monogamous unions, and the same proportion were married. The

\footnotetext{
*The following household characteristics and assets were used to create the wealth score: land ownership, toilet type, drinking water source, bed, table, chair, dresser, refrigerator, separate freezer, microwave, food processor, washing machine, vacuum cleaner, cassette player, CD player, DVD player, color TV, black and white TV, VCR, tape recorder, stereo sound system, camera, video camera, landline phone, cell phone, sewing machine, personal computer, motorcycle, bicycle, car or truck, horse or cart, motor boat or yacht, and generator.
}

TABLE 2. Selected characteristics of couples of reproductive age, and men's and women's reports on five dimensions of relationship quality, Family Health and Wealth Survey, Kumasi, Ghana, 2010

Variable

Mean or \% $(\mathrm{N}=698)$

CONTRACEPTIVE BEHAVIOR

Contraceptive use (\%)

No method

Nonawareness method

Awareness method

RELATIONSHIP QUALITY

Commitment score (range, 4-36)

Women

Men

29.9

Trust score (range, 5-35)

Women

Men

28.7

Constructive communication score (range, 3-30)

Women

Men

21.8

25.5

Destructive communication score (range, 3-30)

Women

4.9

Men

Satisfaction score (range, 1-6)

Women

4.5

Men

WOMEN

Age

Education (yrs.)

Religion (\%)

Christian

Muslim

HOUSEHOLD/COUPLE

Household wealth quintile (\%)

Lowest

Lower

Middle

Higher

Highest

Relationship type (\%)

Monogamous

Polygynous

Relationship status (\%)

Married

Cohabiting

Relationship duration (yrs.)

Difference in age (yrs.)

Difference in education (yrs.)

No. of children

Notes: Unless noted otherwise, all figures are means. Men were aged 18-59 and women were aged $18-44$.

mean duration of relationships was 12 years, and the mean number of children was three.

About three-fourths of women reported not using any contraceptive method at the time of the survey. Eleven percent reported relying on a method that could be used without their partner's knowledge, and 12\% a method that would typically require both partners' knowledge. The pill was the most commonly used nonawareness method, followed by the injectable; among awareness methods, peri- 
TABLE 3. Unadjusted relative risk ratios (and 95\% confidence intervals) from multinomial logistic regression analysis identifying associations between contraceptive method use and selected characteristics

\begin{tabular}{l} 
Characteristic \\
\hline RELATIONSHIP QUALITY \\
Commitment score \\
Women \\
Men \\
Trust score \\
Women \\
Men
\end{tabular}

Nonawareness method vs. no method

Awareness method vs.no method

Constructive communication score Women

Men

Destructive communication score Women

Men

Satisfaction score

Women

Men

WOMEN

Age

Education (yrs.)

Religion

Christian (ref)

Muslim

HOUSEHOLD/COUPLE

Household wealth quintile

Lowest (ref)

$\begin{array}{ll}1.00(0.96-1.05) & 1.02(0.97-1.07) \\ 1.07(0.95-1.22) & 1.08(1.03-1.12)^{* * *} \\ 0.99(0.95-1.04) & 1.02(0.94-1.10) \\ 1.05(0.99-1.12) & 1.04(0.97-1.11) \\ & \\ 1.00(0.97-1.03) & 1.05(1.03-1.06)^{* * *} \\ 1.05(0.98-1.12) & 1.16(1.13-1.18)^{* * *} \\ & \\ 1.06(0.98-1.15) & 1.05(0.99-1.12) \\ 0.93(0.84-1.02) & 0.97(0.87-1.09) \\ & \\ 0.96(0.85-1.09) & 1.17(1.01-1.34)^{*} \\ 1.35(0.94-1.95) & 1.31(0.83-2.07) \\ & \\ 0.94(0.91-0.98)^{* * *} & 0.95(0.90-1.00) \\ 1.07(1.04-1.11)^{* * *} & 1.09(0.91-1.31) \\ 1.00 & 1.00 \\ 0.46(0.26-0.83)^{* *} & 0.68(0.30-1.58)\end{array}$

1.00
Lower

Middle

Higher

Highest

\section{Relationship type}

Monogamous (ref)

Polygynous

Relationship status

Married (ref)

Cohabiting

Relationship duration (yrs.)

Difference in age (yrs.)

Difference in education (yrs.)

No. of children

$1.17(0.59-2.31)$

$0.86(0.45-1.63)$

$0.59(0.21-1.64)$

$0.75(0.40-1.41)$

$\begin{array}{ll}1.00 & 1.00 \\ 0.27(0.15-0.48)^{* * *} & 0.12(0.01-2.41) \\ & \\ 1.00 & 1.00 \\ 1.17(0.31-4.45) & 0.90(0.21-3.80)\end{array}$

$0.98(0.95-1.01)$

$0.96(0.92-1.01)$

$0.96(0.94-0.98)^{* * *}$

$1.01(0.87-1.17)$

$1.24(0.28-5.44)$

$1.22(0.90-1.64)$

$1.29(0.51-3.29)$

$1.80(0.59-5.44)$

${ }^{*} \mathrm{p} \leq .05 .{ }^{* *} \mathrm{p} \leq .01 .{ }^{* * *} \mathrm{p} \leq .001$. Notes: Nonawareness methods include the injectable, pill, IUD, implants and diaphragm. Awareness methods include periodic abstinence, withdrawal, condoms and spermicides. ref=reference group. and 1.2, respectively, per one-point increase-Table 3). None of the dimensions of relationship quality as reported by either gender was associated with use of nonawareness methods. Men's commitment and constructive communication scores were positively associated with using an awareness method rather than no method (1.1 and 1.2, respectively)

Several other independent variables were correlated with contraceptive use. Notably, women's education was positively correlated with use of a nonawareness method as opposed to nonuse (relative risk ratio, 1.1 for each additional year), whereas the difference in partners' education level was negatively correlated with using a nonawareness method ( 0.96 for each additional year of education for the man). Women's age, being Muslim and being in a polygynous union were negatively associated with using a nonawareness method as opposed to none (0.3-0.9), and relationship duration was negatively correlated with using an awareness method rather than no method ( 0.97 for each additional year).

\section{Multivariate Analysis}

In the adjusted analysis, the relationship between women's constructive communication scores and use of an awareness method rather than no method lost significance (Table 4). The positive association between women's satisfaction scores and awareness method use showed increases in both the relative risk ratio (1.2 for each one-point increase) and the level of significance. The positive association between men's scores on constructive communication and use of an awareness method rather than no method remained significant (1.1), while the association between their commitment scores and use of awareness methods lost significance. In the multivariate models, men's trust and constructive communication scores were positively associated with use of a nonawareness method rather than no method (1.1 for each one-point increase).

For the other independent variables, most of the associations found in the unadjusted analysis remained significant in the adjusted analysis (not shown). Notably, the association between partners' difference in education level and use of a nonawareness method as opposed to none remained highly significant (relative risk ratio, 0.95; $<<.001$ ). The number of children, which was not associated with use of nonawareness methods in the unadjusted analysis, was positively associated with such use in the adjusted analysis (1.3; $<<.01)$. Finally, two positive associations in the bivariate analysis-between women's education level and use of nonawareness methods, and between relationship duration and use of awareness methods-lost significance in the multivariate analysis.

\section{DISCUSSION}

To our knowledge, this is one of the first studies to investigate the association between relationship quality and contraceptive use in Sub-Saharan Africa. In general, both men and women rated their relationships positively; how- 
ever, men tended to give higher ratings. This was expected, given that Ghana remains a patriarchal society and women typically enjoy less power and autonomy in marriage than men; nonetheless, the possible detrimental consequences of inequality on women's health could be substantial. A literature review of research on family and health showed that some studies have found that marriage is associated with stronger health benefits for men than for women, while others have found no differences. ${ }^{44}$ Gender differences in the perception or experience of marriage could affect individuals' and couples' sexual and reproductive health, and this topic deserves further investigation.

Overall, the associations between relationship quality and use of awareness methods were stronger than those between relationship quality and use of nonawareness methods. This was especially true for measures of women's satisfaction and men's constructive communication. These findings are not surprising given that awareness methods typically require acceptance and cooperation from both partners, which is likely easier to achieve in a high-quality relationship than in a low-quality relationship. The ability to communicate in a constructive and positive manner may help couples initiate discussion about and use of contraceptives, regardless of method type. This ability may also be helpful in contraceptive continuation, especially for couples using an awareness method.

We found evidence that relationship attributes other than relationship quality were important in the use of nonawareness methods. Most notably, a strong negative association between partners' difference in education level and nonawareness method use was seen in both unadjusted and adjusted analyses: The greater the education gap between partners, the less likely they were to use a nonawareness method as opposed to none. It is possible that educational differences may influence the use of nonawareness methods indirectly by altering the dynamics in the relationship, such as creating a power imbalance or weakening communication. An important next step in future analyses is to improve our understanding of how and why educational differences are associated with contraceptive use as well as with relationship quality.

Constructive communication was the only dimension correlated with use of both awareness and nonawareness methods. Previous research has shown that couples' communication about family planning is associated with contraceptive use, $3,8,9,14$ but this is one of the first studies conducted in Sub-Saharan Africa to investigate the quality and characteristics of communication between partners. Our findings have begun to fill a gap in the literature; however, more research is needed to fully understand the links between partner communication and contraceptive use.

Men's trust and constructive communication measures were the only two dimensions of relationship quality associated with the use of nonawareness methods. As previously noted, qualitative studies have shown that some men do not want their partners to use female-controlled methods because of a lack of trust in their partners. ${ }^{15,18}$
TABLE 4. Adjusted relative risk ratios (and 95\% confidence intervals) from multinomial logistic regression analysis identifying associations between contraceptive method use and relationship quality variables

Variable

Nonawareness method Awareness method vs.no method vs.no method

\begin{tabular}{lll}
\hline Commitment score & $1.00(0.97-1.04)$ & $1.02(0.98-1.07)$ \\
Women & $1.08(0.97-1.20)$ & $1.06(0.99-1.13)$ \\
Men & & \\
Trust score & $1.00(0.96-1.04)$ & $1.00(0.93-1.08)$ \\
Women & $1.05(1.00-1.09)^{*}$ & $1.01(0.92-1.10)$ \\
Men & & \\
Constructive communication score & $0.98(0.95-1.00)$ & $1.01(0.96-1.06)$ \\
Women & $1.08(1.01-1.17)^{*}$ & $1.14(1.07-1.22)^{* * *}$ \\
Men & & \\
Destructive communication score & $1.05(1.00-1.11)$ & $1.05(0.98-1.12)$ \\
Women & $0.93(0.81-1.06)$ & $0.98(0.89-1.08)$ \\
Men & & \\
Satisfaction score & $1.02(0.97-1.07)$ & $1.22(1.10-1.34)^{* * *}$ \\
Women & $1.28(0.83-1.98)$ & $1.07(0.77-1.49)$ \\
Men &
\end{tabular}

${ }^{*} \mathrm{p} \leq .05 .{ }^{* * *} \mathrm{p} \leq .001$. Notes: Nonawareness methods include the injectable, pill, IUD, implants and diaphragm. Awareness methods include periodic abstinence, withdrawal, condoms and spermicides. Models adjusted for partner's relationship quality scores and all independent variables.

These men are afraid that if their partner uses a femalecontrolled method, she will be more likely to be unfaithful. Our results suggest that women with trusting partners are more likely than women with less-trusting partners to use a nonawareness method rather than none. Neither women's nor men's trust scores were associated with use of an awareness method as opposed to no method.

Our findings also showed that for some dimensions of relationship quality, the man's evaluation of his relationship appeared to play a more influential role in women's contraceptive use than her evaluation. If a woman's partner is content with the relationship and she is aware of her partner's feelings, then she may feel more confident in taking risks by discussing contraception with her husband (often a taboo topic in countries such as Ghana) or by using contraceptives with or without her partner's approval. In contrast, a woman's perception that her partner is dissatisfied with their relationship could make her more cautious and less likely to do something that might cause problems, such as discussing or using contraceptives. Another hypothesis for why women in lower-quality relationships are less likely than others to use contraceptives is that they have sex less frequently and so have a decreased need for contraception.

It is also possible that women in relationships characterized by negative attributes are more motivated to prevent pregnancy because they cannot guarantee the survival of the relationship or are uncertain how a child will affect the relationship. These women might also worry about raising a child in a negative environment. We did not find evidence that low scores on relationship measures were correlated with any type of contraceptive use; however, if relationship quality can have opposite effects on contraceptive use depending on the circumstances, this might reduce 
the strength of the associations observed in our analysis and may be masking existing relationships. Wilson and Koo hypothesized and subsequently found supporting evidence that relationship quality was both positively and negatively correlated with women's contraceptive use. ${ }^{26}$ They suggested that high-quality relationships are associated with contraceptive nonuse because of a reduced motivation to avoid pregnancy, but that such relationships may also facilitate contraceptive use-for example, through better communication or support. This issue is important to consider in future research on relationship quality and reproductive outcomes.

Our decision to categorize contraceptive use by nonuse, use of an awareness method and use of a nonawareness method is unique. This decision was based on the hypothesis that the way in which a couple's relationship quality influences contraceptive use may depend on how involved one's partner needs to be in the decision-making process and actual use of a specific method. Similar categorization has been used in other studies, including one on women's empowerment and choice of contraceptive method. ${ }^{7}$ Ideally, we would have examined each method separately; however, because of the low contraceptive prevalence rate in our sample we were unable to do so. Furthermore, future studies should consider looking at relationship quality and covert method use in settings with high levels of such use.

\section{Limitations}

Our study has a number of limitations. There are numerous dimensions of relationship quality, and we included just five in our analysis. Since the scales were constructed in developed countries and have not been widely used in African settings, some participants as well as interviewers may have been uncomfortable with the questions or the Likert scales. Additionally, measures of relationship quality and contraceptive use rely on self-report, which is subject to social desirability bias. Regarding relationship quality, participants may have been afraid or embarrassed to report negative feelings about their relationship, especially if they were concerned that their partner would find out. Furthermore, contraceptive use was reportedly low in our sample, which may have influenced women's willingness to acknowledge use.

Another limitation is the use of a cross-sectional design, which prevents the determination of causality or timing of events. For example, we were unable to determine if relationship quality affects contraceptive use or vice versa, or both. Longitudinal studies are needed to further explore the associations identified in this study.

\section{Conclusions}

Despite these limitations, there are programmatic implications that can be considered and incorporated into programs. For example, family planning campaigns should consider how women, men and couples are targeted and included in activities. Mass media campaigns that aim to promote contraceptive use could integrate messages about healthy relationships and decision making into their strategy. Furthermore, guidelines and training for family planning providers need to expand beyond clinical care to include the social and behavioral components of using contraceptives. Providers need to be prepared to counsel individuals and couples in both healthy and unhealthy relationships to help them achieve their reproductive goals. While it is important for programs to promote higherquality relationships as a means of improving family planning, including access to and use of contraceptives, it is equally important to identify and implement strategies that improve access to contraceptives for women in lowquality relationships who may face challenges in exercising their sexual and reproductive rights.

Some countries in Sub-Saharan Africa have not seen the increase in contraceptive prevalence rate experienced in other regions of the world. In Ghana, modern contraceptive use appears to have stagnated while unmet need for family planning remains high. It is essential that we look beyond the common correlates of contraceptive use to fully understand how and why individuals and couples make certain sexual and reproductive decisions. This study provides insight into the link between couples' relationship quality and contraceptive use-an understudied aspect of family planning-and enhances our understanding of contraceptive decision making in a West African setting.

\section{REFERENCES}

1. United Nations, Report of the International Conference on Population and Development, Cairo, Egypt: United Nations, 1994.

2. Singh S and Darroch JE, Adding It Up: Costs and Benefits of Contraceptive Services-Estimates for 2012, New York: Guttmacher Institute and United Nations Population Fund, 2012, <http://www.guttmacher.org/pubs/ AIU-2012-estimates.pdf>, accessed Sept. 24, 2013

3. Salway S, How attitudes toward family planning and discussion between wives and husbands affect contraceptive use in Ghana, International Family Planning Perspectives, 1994, 20(2):44-47 \& 74

4. Alio AP et al., Intimate partner violence and contraception use among women in Sub-Saharan Africa, International Journal of Gynecology \& Obstetrics, 2009, 107(1):35-38

5. Oyedokun AO, Domestic violence and constrained contraceptive choices in selected areas of Osun State, Nigeria, Sexual and Relationship Therapy, 2008, 23(4):305-323.

6. Bogale B et al., Married women's decision making power on modern contraceptive use in urban and rural southern Ethiopia, BMC Public Health, 2011, Vol. 11, Art. 342, <http://www.biomedcentral.com/14712458/11/342>, accessed Sept. 5, 2013.

7. Do M and Kurimoto N, Women's empowerment and choice of contraceptive methods in selected African countries, International Perspectives on Sexual and Reproductive Health, 2012, 38(1):23-33.

8. Bawah AA, Spousal communication and family planning behavior in Navrongo: a longitudinal assessment, Studies in Family Planning, 2002, 33(2):185-194.

9. Klomegah R, Spousal communication, power, and contraceptive use in Burkina Faso, West Africa, Marriage \& Family Review, 2006 , 40(2-3):89-105

10. Woldemicael G, Women's autonomy and reproductive preferences in Eritrea, Journal of Biosocial Science, 2009, 41(2):161-181.

11. Upadhyay UD and Hindin MJ, Do higher status and more autonomous women have longer birth intervals? Results from Cebu, Philippines, Social Science \& Medicine, 2005, 60(11):2641-2655. 
12. Diop-Sidibé N, Campbell JC and Becker S, Domestic violence against women in Egypt-wife beating and health outcomes, Social Science \& Medicine, 2006, 62(5):1260-1277.

13. Hindin MJ and Muntifering CJ, Women's autonomy and timing of most recent sexual intercourse in Sub-Saharan Africa: a multi-country analysis, Journal of Sex Research, 2011, 48(6):511-519.

14. Izugbara $C$ et al., Gendered interests and poor spousal contraceptive communication in Islamic northern Nigeria, Journal of Family Planning and Reproductive Health Care, 2010, 36(4):219-224.

15. Bawah AA et al., Women's fears and men's anxieties: the impact of family planning on gender relations in northern Ghana, Studies in Family Planning, 1999, 30(1):54-66.

16. Montgomery CM et al., The role of partnership dynamics in determining the acceptability of condoms and microbicides, AIDS Care, 2008, 20(6):733-740.

17. Akinleye GA and Alade FA, Relationships among family planning, sexual fulfillment and marital satisfaction of married people in Lagos State, Nigeria, Social Sciences, 2008, 3(5):343-346.

18. Pool R et al., Men's attitudes to condoms and female controlled means of protection against HIV and STDs in south-western Uganda, Culture, Health \& Sexuality, 2000, 2(2):197-211.

19. Manlove J et al., Relationship characteristics and contraceptive use among young adults, Perspectives on Sexual and Reproductive Health, 2011, 43(2):119-128

20. Ku L, Sonenstein FL and Pleck JH, The dynamics of young men's condom use during and across relationships, Family Planning Perspectives, 1994, 26(6):246-251.

21. Manlove J, Ryan S and Franzetta K, Contraceptive use patterns across teens' sexual relationships: the role of relationships, partners, and sexual histories, Demography, 2007, 44(3):603-621.

22. Sayegh MA et al., The developmental association of relationship quality, hormonal contraceptive choice and condom non-use among adolescent women, Journal of Adolescent Health, 2006, 39(3):388-395.

23. Manning WD et al., Relationship dynamics and consistency of condom use among adolescents, Perspectives on Sexual and Reproductive Health, 2009, 41(3):181-190.

24. Harvey SM et al., A conceptual model of women's condom use intentions: integrating intrapersonal and relationship factors, AIDS Care, 2006, 18(7):698-709.

25. Bianchi-Demicheli $\mathrm{F}$ et al., Contraceptive practice before and after termination of pregnancy: a prospective study, Contraception, 2003, 67(2):107-113

26. Wilson EK and Koo HP, Associations between low-income women's relationship characteristics and their contraceptive use, Perspectives on Sexual and Reproductive Health, 2008, 40(3):171-179.

27. Ghana Statistical Service (GSS), Ghana Health Service (GHS) and ICF Macro, Ghana Demographic and Health Survey, 2008, Accra, Ghana: GSS, GHS and ICF Macro, 2009.

28. Takyi BK and Gyimah SO, Matrilineal family ties and marital dissolution in Ghana, Journal of Family Issues, 2007, 28(5):682-705

29. Bove R and Valeggia C, Polygyny and women's health in subSaharan Africa, Social Science \& Medicine, 2009, 68(1):21-29.

30. Omari TP, Changing attitudes of students in West African society toward marriage and family relationships, British Journal of Sociology, 1960, 11(3):197-210.

31. Oheneba-Sakyi Y, Female Autonomy, Family Decision Making, and Demographic Behavior in Africa, Lewiston, NY, USA: Edwin Mellen Press, 1999.

32. Takyi BK and Broughton CL, Marital stability in sub-Saharan Africa: Do women's autonomy and socioeconomic situation matter? Journal of Family and Economic Issues, 2006, 27(1):113-132.

33. Miller NB and Kannae LA, Predicting marital quality in Ghana, Journal of Comparative Family Studies, 1999, 30(4):599-615.
34. Abane H, For better, for worse: social dimensions of marital conflict in Ghana-the case of Cape Coast, Gender \& Behaviour, 2003, $1(1): 34-54$

35. Hindin MJ, McGough LJ and Adanu RM, Misperceptions, misinformation and myths about modern contraceptive use in Ghana, Journal of Family Planning and Reproductive Health Care, 2013, doi:10.1136/ jfprhc-2012-100464, accessed Sept. 5, 2013

36. Hong R et al., Ghana Trend Analysis for Family Planning Services, 1993, 1996, and 2002, Calverton, MD, USA: ORC Macro, 2005

37. Broderick CB, Understanding Family Process: Basics of Family Systems Theory, Newbury Park, CA, USA: Sage, 1993.

38. Sternberg RJ, Construct validation of a triangular love scale, European Journal of Social Psychology, 1997, 27(3):313-335.

39. Larzelere RE and Huston TL, The Dyadic Trust Scale: toward understanding interpersonal trust in close relationships, Journal of Marriage and the Family, 1980, 42(3):595-604.

40. Heavey CL et al., The Communication Patterns Questionnaire: the reliability and validity of a constructive communication subscale, Journal of Marriage and the Family, 1996, 58(3):796-800.

41. Christensen A and Sullaway M, Communication Patterns Questionnaire, unpublished manuscript, Los Angeles, CA, USA: University of California, Los Angeles, 1984.

42. Spanier GB, Measuring dyadic adjustment: new scales for assessing the quality of marriage and similar dyads, Journal of Marriage and the Family, 1976, 38(1):15-28

43. Muntifering C, Couple Relationship Quality and Contraceptive Decision-Making in Kumasi, Ghana, Baltimore, MD, USA: Johns Hopkins University, 2011.

44. Carr D and Springer KW, Advances in families and health research in the 21st century, Journal of Marriage and Family, 2010, 72(3):743761

\section{RESUMEN}

Contexto: Existe un rico acervo de datos sobre conocimientos, actitudes y prácticas relacionados con el uso de anticonceptivos; sin embargo, los aspectos emocionales de las relaciones, que pueden influir en la toma de decisiones reproductivas, son a menudo ignorados.

Métodos: Se usaron datos de la Encuesta de Salud y Riqueza Familiar de 2010, mediante un análisis de regresión logística bivariada y multinomial, con el fin de identificar correlaciones entre la calidad de la relación y el uso actual de anticonceptivos en 698 parejas de Kumasi, Ghana, que están casadas o viven en cohabitación. Los indicadores sobre la calidad de la relación consistieron en cuatro escalas para medir el compromiso, la confianza, la comunicación constructiva y la comunicación destructiva, y en una pregunta sobre la satisfacción general con la relación. El uso actual de anticonceptivos se dividió en tres categorías: no se usa ningún método; uso de un método discreto (inyectable, píldora, DIU, implante y diafragma); uso de un método evidente (abstinencia periódica, retiro, condones y espermicida)

Resultados: El uso general de anticonceptivos es bajo: un $22 \%$ de las mujeres afirmaron estar usando algún método en la actualidad. En general, las personas participantes reportaron altos niveles de calidad para sus relaciones. Entre las mujeres, los puntajes de satisfacción con la relación están positivamente asociados con el uso de métodos evidentes, más que con el no uso (cociente de riesgo relativo, 1.2). Entre los hombres, los puntajes de confianza están positivamente asociados con 
el uso de métodos discretos, más que con el no uso (1.1), y los puntajes de comunicación constructiva, con el uso de ambos tipos de método, más que con el no uso (1.1 cada uno).

Conclusiones: La calidad de la relación de las parejas parece ser un elemento importante en la toma de decisiones sobre el uso de anticonceptivos, y debe tomarse en cuenta en el diseño e implementación de los programas y políticas de planificación familiar.

\section{RÉSUMÉ}

Contexte: La connaissance, les attitudes et les pratiques relatives à l'usage de la contraception sont abondamment documentées. Les aspects affectifs des relations susceptibles d'influencer la décision en matière de procréation sont cependant souvent omis.

Méthodes: Les données de l'enquête 2010 sur la santé et la richesse des familles ont servi à la réalisation d'analyses de régression logistique bivariées et multinomiales, afin d'identifier les associations entre la qualité de la relation et la pratique contraceptive courante de 698 couples mariés ou en concubinage à Kumasi (Ghana). Les indicateurs de qualité de la relation se mesurent sur quatre échelles - engagement, confiance, communication constructive et communication destructive -, avec aussi une question de satisfaction au sein de la relation. La pratique contraceptive courante est répartie en trois catégories: aucune, méthode discrète (injectable, pilule, stérilet, implant et diaphragme) et méthode évidente (abstinence périodique, retrait, préservatif et spermicide).

Résultats: La pratique contraceptive globale s'est révélée faible - avec $22 \%$ de femmes déclarant ne pratiquer aucune méthode au moment de l'enquête. En général, les répondants font état de hauts niveaux de qualité de la relation. Les cotes de satisfaction des femmes au sein de la relation présentent une association positive avec la pratique des méthodes évidentes plutôt que l'absence de pratique (rapport de risque relatif, 1,2). Côté masculin, les cotes de confiance sont associées positivement à la pratique des méthodes discrètes plutôt qu'à l'absence de pratique $(1,1)$ et celles de communication constructive le sont aux deux types de méthodes plutôt qu'à l'absence de pratique (1,1 chacun).

Conclusions: La qualité de la relation des couples semble jouer un rôle important dans leur décision relative à la pratique contraceptive. Il convient d'en tenir compte dans les efforts de conception et de mise en ouvre des programmes et politiques de planification familiale.

Author contact: cariecox@uw.edu 